\title{
Post-fabrication and putting on a show: examining the impact of short notice inspections.
}

Andrew Clapham*

University of Nottingham, UK

This paper explores inspection, performativity and fabrication within the context of two English schools. Case studies are employed to compare and contrast the inspection experiences of two teachers at different points in their career trajectories. The paper focuses on comments made by Sir Michael Wilshaw, the head of the Office for Standards in Education (OfSTED), that schools were 'putting on a show' during inspections. Empirical evidence is presented which suggests that the key informants invested emotional, physical and intellectual capital into the perpetual readiness incumbent in high-stakes inspection process - an investment which was anything other than putting on a show. The paper proposes that, in the cases in point, the changing nature of school inspections led to 'post-fabrication', that is, inspection readiness was omnipresent to such an extent that it was not a fabricated version of events. The findings presented here have implications for teachers, school leadership teams, policy makers and all those interested in inspection.

\section{Introduction}

School inspection is a national and international phenomenon. The Office for Standards in Education (OfSTED) is the regulatory body which inspects educational organisations in England. In early 2013 Sir Michael Wilshaw, the head of OfSTED, warned schools that they should not attempt to pull the 'proverbial wool' over inspectors' eyes by

\footnotetext{
* School of Education, University of Nottingham, Nottingham, NG8 1BB, UK. Email: andrew.clapham@nottingham.ac.uk
} 
presenting activities which did not reflect normal school life. Wilshaw continued by saying that a teacher 'putting on a show' was deeply irritating for inspectors and insisted that there was no preconceived, or 'OfSTED preferred', teaching style.

This paper examines the interrelationship between performativity, school inspection, and 'fabrications' (Ball, 2001). Inspection has been the focus of educational research (Jeffrey and Woods, 1998; Perryman 2006, 2009) as has fabrication and performativity (Ball, 1998; Nicholl and McLellan, 2008; Morgan et al, 2010; Clapham, 2013). The paper explores the experiences of inspection of two teachers, Omar and Mia, who work at Long Ridge Park and Willow Tree schools ${ }^{1}$. Mia and Omar were chosen as the key informants so as to compare and contrast the inspection experiences of teachers, one at the beginning of their career, and the other heading towards the end of it. Through these two case studies, this paper examines instances as to whether Wishaw's policy narrative of schools putting on a show played out in the informants' experiences of inspection.

\section{Inspection}

This paper explores OfSTED's current inspection framework. Before doing so however, it is important to highlight the changes to the inspection system in England and how these have impacted upon the capabilities of teachers and schools to fabricate inspection.

OfSTED inspections are conducted under section 5 of the Education Act 2005 amended in 2012. As a result of the 2005 Act, OfSTED introduced 'short notice inspections' where schools were inspected over two or three days of visits with two days' notice. This model replaced the previous system where schools were given two

\footnotetext{
${ }^{1}$ The names of schools and informants in this study are pseudonyms
} 
months to prepare for inspection ${ }^{2}$. Central to the 2005 model, was the stipulation that schools should complete and update a School Evaluation Form (SEF) to evidence schools being aware of their strengths and weaknesses (OfSTED 2011). The 2012 amendments required inspectors to be provided with a greater range and more detailed information than that presented in the pre 2012 SEF (OfSTED, 2014b).

From 2012, schools are ranked as outstanding, good, requires improvement or inadequate. Within the inadequate ranking, schools can have serious weaknesses or require special measures. The differences in these rankings reflect the frequency, and extent, of subsequent inspections and relate to the school's 'overall effectiveness' (OfSTED, 2012, 17) which is obtained through inspecting (a) student achievement; (b) quality of teaching; (c) pupil behaviour and safety; (d) quality of leadership and management.

Schools ranked as having serious weaknesses or put into special measures signal further inspections and, if improvement is not made, the possibility of fundamental reorganisation of management and teaching provisions and ultimately closure (OfSTED, 2012). A school ranked as good will be inspected within five years of the end of the school year in which its last inspection took place. For those schools ranked as subject to notice to improve, this reduces to within a six to eight month window after the last section 5 inspections.

As indicated by the 2012 amendments, school inspection is a changing landscape and short notice inspection have themselves been reviewed. In late January 2014, OfSTED announced it would be conducting 'no notice' inspections of schools

\footnotetext{
${ }^{2}$ Under the 2012 amendments, schools are usually informed by telephone on the afternoon of the working day prior to the inspection
} 
where poor student behaviour had been identified as a concern (OfSTED, 2014a, no page $)^{3}$.

\section{Performativity}

Inspection is a key performative tool (Perryman, 2006). Performativity mediates the measurement of productivity, and with it the 'value' of a school, and endorses techniques where practitioners are organised, and organise themselves, in response to evaluative tools (Ball, 2003). Performativity promotes self-regulation with schools developing systems based upon performance management, target setting, appraisal and the analysis of school effectiveness outputs (Craft, 2005). Performativity research draws on the work of Lyotard $(1979,27)$ and what he calls the 'legitimation of knowledge'. For Lyotard, performativity is defined by how knowledge is constituted, how knowledge is considered as being of worth and what knowledge has legitimacy.

Lyotard argues that performativity gives rise to the commodification of knowledge through a 'context of control' (Lyotard, 46-7). Teachers' professional lives are controlled through the legitimation of scientific knowledge at the expense of narrative knowledge. Moreover, the use value of knowledge is paramount, as knowledge is valued as an indicator of performative requirements rather than having value in itself (Jeffrey and Troman, 2011). Performativity is reflected in the increased measurement of performance, with examination grades such as the General Certificate

${ }^{3}$ In March 2014, further reforms were outlined by OfSTED which changed the process of school inspection to a model where schools rated as good or outstanding would be inspected over a single day, by one inspector, every two years. The model would remain the same for schools not rated good or better. 
in Secondary Education $(\mathrm{GCSE})^{4}$, being key indicators of student and teacher performance, school effectiveness, and a central part of the inspection process (Nicholl and McLellan, 2008).

Foucault's work - particularly Discipline and punish (1977) - has been used to examine school inspection. By Drawing on Foucault, Perryman (2006) examines how 'Panoptic performativity' plays out in school inspection regimes which she proposes can be treated as a Panoptic, and disciplinary, process. Within Panoptic performativity, failing schools are placed under the threat of constant inspection and surveillance. Schools that have a successful inspection are still under this threat, but have a much longer time period between inspections; what Perryman calls $(2009,628)$ 'the lighter touch'. The constant threat of inspection mediates panoptic and performative disciplinary mechanisms of the omnipresent watcher regardless as to whether schools are under inspection or not. As a result, schools and teachers are in a 'state of perpetual readiness' (Perryman, 2009, 627).

The surveillance inherent in performativity might be expected to be resisted. However, Priestley et al (2012) examine the lack of such resistance and highlight that teachers increasingly see performative surveillance as an inherent, and thus accepted, part their work. The acceptance of performative conditions results in teachers submitting to panoptic surveillance, through internal and external inspection, which

\footnotetext{
${ }^{4}$ The end of compulsory schooling in England at Year 11 is signified by many students taking
} GCSE examinations. The number of A*-C GCSE grades attained by its students govern the position a school holds in national performance league tables and form part of the data set used by inspectors to rank effectiveness. 
leads to what Scott (2010) calls an inmate culture where teachers collude in their own disempowerment.

Performative conditions are part in the neo-liberal transformation of education through the market and audit cultures (Apple, 2005; Power, 1999). Performativity and the market require that schools have to present themselves as a product to be consumed, with the inspection process a tool which ranks the quality of the product on offer. To be successful in inspection, teachers are 'inwardly focussed upon the survival of their institutions within the education market' (Ball, 1998, 198). Schools have to demonstrate success in the market and in doing so reproduce government led 'performative dominant discourses' (Jeffrey and Troman, 2012, 85) with self-surveillance and evaluation increasingly prevalent (Fidler et al, 1998; Policy exchange, 2014).

The market, inspection, performativity and neo-liberalism underpin 'selfgovernment' (Rose, 1999, p. 264) which reduces the role of the state in supporting the population. For its proponents, a neo-liberal education system highlights the rise of the individual and the reduction of regulation. This is however challenged, for example by Ozga (2009), who suggests that regulatory tools such as inspection only mediate an appearance of deregulation.

\section{Fabrication}

A corollary of a performative environment is fabrication. Fabrications are the production of representations or versions of an organisation or individual for the purpose of inspection (Ball, 2001). Ball (2003) describes schools focusing on metrics, such as $\mathrm{A}^{*}$-C GCSE grades, purely for the purpose of achieving a good inspection report as a prominent example of such fabrications.

Schools have of course focussed on the examination grades attained by their students for many years. Equally, these grades have been used both officially and 
unofficially as a means for assessing how 'good' a school is for many years. However, in performative conditions, examinations have become metrics which directly relate to school effectiveness and are used as a means through which accountability is apportioned through inspection. This has had the result that the temptation for schools to fabricate conditions leading to increased examination attainment purely to negotiate inspection is increasingly prevalent (Thomson et al, 2010).

Fabrications are part of the culture associated with inspection where schools 'game' the system so as to best ensure success in meeting inspection requirements (Nicholl and McLellan, 2008). Gaming can be seen as a means by which schools can successfully negotiate the inspection process by 'fabricating the stage' (Perryman, 2009, 622). However, gaming strategies lead to fabrications concealing, as much as exposing, the very auditable process under inspection due to the 'improvement game' (Ball, 2003, 225).

Fundamental to fabrications, is that 'truthfulness is not the point' and that fabrications, are consequently 'outside the truth' (Ball, 2003, 224) as they are produced purely to be accountable. This is a key point in Ball's analysis. Fabrications do not reflect the day-to-day activities in schools as they are only for the inspector. Indeed, as soon as the inspector leaves then the normal, non-fabricated, patterns of school life return.

\section{The study}

The research question asked:

- How did inspection play out in the informants' working lives?

The study built on the tradition of ethnographic research of inspection and performativity (Jeffrey and Woods, 1998; Troman, 2000; Clapham, 2013) and utlised field notes, interviews and observations. The data generated by two teachers in 
different schools and at different points in their career trajectories gave a contrast in inspection experiences.

The researcher visited Long Ridge Park and Willow Tree schools as a visitor which gave an 'outsiders' lens. Moving around the schools, talking to teachers, support staff and students as well as observing lessons gave the opportunity to become embedded, as much as a visitor can, within the schools. For example, one critical incident occurred during a lunch period in the staff room at Long Ridge Park where data was generated from a heated debate between informants who were discussing the presence of OfSTED inspectors at a school in the local area.

Reflexive interviewing (Hammersley and Atkinson, 1995, 113) was employed as the primary data generation tool. This model of interviewing was semi-structured (Kvale and Brinkman, 2009) in so far as inspection was the primary topic of conversation between informants and researcher. Prior to each interview, a 'script' was prepared with key points for discussion. These points emerged from the grounded theory analysis of previous interviews and analysis of the literature. The script was not however strictly binding and there were occasions where the informants' discussion opened up directions not included in the script.

As well as the two key informants, interview data was generated by a number of other actors in the two settings. There were 11 interviews with the key informant which were triangulated with a further 10 interviews with other teachers. There were also 10 observations of the key informants teaching lessons. For Denzin (1970, p. 310), using different methods to generate data indicates 'method triangulation'. Triangulation was a method of verification, or refutation, of informants' claims through drawing on different data sources so as to develop a multi-layered view of the research setting. Observations 
were unstructured (Delamont, 1976) and were used both to triangulate informants' claims and to generate data in their own right without reference to previous events.

Analysis employed grounded theory (Glaser and Strauss 1967) so as to identify concepts and categories. From drawing on grounded theory literature (see for example, Strauss and Corbin, 1998; Charmaz, 2005), analysis used coding to identify concepts and categories. Open coding, amended from Charmaz (2005, p 518), yielded concepts, which were grouped to make categories. From the data analysis, 3 primary concepts emerged which formed the 'inspection and post-fabrication' category in Table 1.

\section{TABLE INSERTED HERE}

Table 1. Inspection and post fabrication category and concepts

A project such as this, which focuses on a single researcher and a small number of key informants, requires acknowledgment of researcher subjectivity and reflexivity. Reflexivity acknowledges 'past experiences and prior knowledge' (Wellington, 2000, 44) and challenges the notion that data can be 'free' from researcher influence (Hamersley and Atkinson, 1995, 14). Consequently, data analysis and interpretations were shared with the key informants for verification and to support the reflexive process. Triangulation gave the researcher the opportunity to explore the data from the perspectives of a range of informants, and in doing so, brought into focus his own assumptions regarding the multiple meanings of the data.

The project adhered to the ethical guidelines of the British Educational Research Association (BERA, 2011). Informants were approached to give permission for data to 
be used either prior, or in some case post, data generation and were given the opportunity for their data to be removed from the project.

\section{The beginning teacher - Mia}

Mia was a beginning teacher (see Gu and Day, 2013). She was a 23 years old science teacher and was in her second year of teaching. Willow Tree was her first teaching post. The most recent OfSTED report ranked Willow Tree as good. Mia painted a picture of a teacher who, although happy working in the classroom, wanted to pursue promotion.

A recurring concept in Mia's data was how she described the threat of OfSTED inspection, and the school's fixation on the number of $\mathrm{A}^{*}-\mathrm{C}$ examination grades, was the key driver. For example, Mia described how in addition to learning walks ${ }^{5}$ there was also what she called "MockSTED" inspections:

The school's all about inspection. I'm observed all the time, by others in my department, by the SLT [Senior Leadership Team], by 'learning walks'. The one that really gets me though are the OfSTED readiness inspections...we just call them MockSTED. (Interview)

Mia was proud of the progress her groups were making and listed lunchtime and after school sessions she ran as examples of her commitment, and that of the students who attended, toward making this progress.

The progress the kids are making isn't by accident. It's down to really hard work. I don't do lessons to fit a 'template' for outstanding lessons. I want to be outstanding. But that doesn't just happen... I can't switch kids on and off ready for a lesson observation or inspection. They aren't stupid [the students]. If I regularly

\footnotetext{
${ }^{5}$ Learning walks were a quality assurance tool where members of the senior management team conducted brief 'drop in' observations of all staff in the school teaching over a 2-3 day period.
} 
have disorganised, boring lessons and then try to be 'all singing and dancing' every time someone comes to watch then the kids will soon say something. (Interview)

Mia's motivation to be outstanding was intrinsic. She did not want to play the inspection game for the game's sake. For her, she wanted to be the best possible teacher she could be for herself and the students she taught. She acknowledged that there were rules associated with the ranking of her lessons and of the school.

We're told about the outstanding OfSTED lesson being three parts, with starters, a main section and a plenary, and with lots of progress and challenge. That's not an OfSTED lesson though, if it's done well that's a good lesson. It's good practice. I'd say that having three parts, starter, a main bit and plenary if it's done formulaically isn't good practice though. (Interview)

Mia, although acknowledging the stress associated with inspection, wanted to be inspected. Her confidence in her ability and the attainment of her students was such that she had what she called an open door policy.

Mia's door was open. Indeed, after unlocking her door the first thing she would do was to retrieve a small wooden wedge from its place on a shelf and prop the door open. (Observation)

Mia outlined how her passion for teaching was continuing to grow. She reported that despite the changing educational landscape being at times frustrating, the work she was able to complete with her classes was enough to keep teaching being something she loved doing. Mia outlined how organisation was crucial to being a successful teacher. Although there was no stipulation for lesson plans at the school, Mia still wrote her own outline for lessons. As she became more confident, these plans reduced in size but she still had a clearly written plan to support her work.

Despite her high levels of organisation, workload did impact on Mia's school life and home life balance. She worked after school but rarely at weekends. However, 
there were occasions, OfSTED readiness observations for example, when extra work impinged on Mia's home life - a demand of these inspections was for a fully completed lesson plan to be provided for every lesson she taught over a two day period.

On the evening before the mock inspection Mia, along with three other members of staff, were still at school at 7.00 completing the required lesson plans. Mia was usually at home by 5.30. (Observation)

She questioned the efficacy of such initiatives, particularly in light of the extra demands they placed on already hard working teachers. Mia regularly worked long hours, a significant part of which she claimed was spent producing lesson plans, student progress check data and reports required for OfSTED inspection.

Mia tried to keep a clear emotional, physical and psychological demarcation between school and home. Mia understood that on occasions this line would become blurred. However, she was demotivated by demands made by the internal OfSTED readiness inspections:

...teachers should be doing the best for their students all the time. And I know most of my colleagues do. Why should we have to change what we do so we're 'inspection ready'...I'm always inspection ready. I have to be. My kids deserve it and I wouldn't be doing my job otherwise. (Interview)

For Mia such requirements were disingenuous at best. Mia felt that inspection was an opportunity to "show off" what was happening in her lessons not to "make something up". Mia's position was that what she did day-to-day was the best she could do. She would not tolerate anything other than that being the case. The structures of what she called "professional trust" resonated with Fullan's (2001) findings regarding teachers' experiencing a lack of professional trust. Mia's view was that her practice was not for 
show, what she did in her classroom was deeply entrenched in her professional identity and constant inspection suggested a lack of trust in her.

\section{The veteran teacher - Omar}

Omar has taught for 26 years, what Day and Gu $(2010,104)$ categorise as a veteran teacher, with the majority of this time being at Long Ridge Park. Omar was 51 years old and has taught in two secondary schools, as a chemistry teacher. Omar was a member of Long Ridge Park's Senior leadership Team (SLT) with the responsibility for inclusion and behaviour. Previous to this he was head of the science faculty. Long Ridge Park was ranked as satisfactory in its most recent OfSTED inspection report ${ }^{6}$. This resulted in a change of head teacher and a revamp of the SLT. The new head indicated that the school should be ranked outstanding in its next inspection.

Teaching was very much a part of Omar's home life. His wife was a deputy head teacher and both his daughters were at university participating on Initial Teacher Education courses. Omar maintained his love for his job. Although interested in his career, he had no intentions of become a head teacher. For Omar, as much inspection was stressful he also found them exciting. Like Mia, he wanted to "show off how good I am". Omar contextualised this statement as he did not want to appear "big headed"; he was proud of his practice, and how hard he and his students worked, and he wanted this to be acknowledged.

There was however a major impact on Omar's work-life home-life balance due to the constant readiness for inspection and the impact of this upon his day-to-day workload. The new head teacher was particularly proactive with regard to OfSTED readiness systems such as learning walks, pre-OfSTED inspections, faculty inspections

\footnotetext{
${ }^{6}$ Since the research completion, Longridge Park has been placed in special measures.
} 
and performance management review observations. Omar maintained that such systems resulted in a negative impact on learning.

I just think all the time spent practicing for inspections should be spent doing what we believe in. We should be moulding the inspection system not it moulding everything we do. (Interview)

This constant readiness, what Omar called "Def Con 1", took its toll on teachers' energy levels and motivation.

I think inspections with little notice are a good thing. Schools have to be constantly on the ball, not just when the inspectors are in. They can't put a show on for the inspectors. (Interview)

Omar reported that inspection was "part and parcel" of his working life and was adamant that what inspectors saw was a reflection of his lessons "day in and day out". He was however, perturbed by the amount of paperwork which was required, and which could easily detract from the time available to plan lessons, talk to students and to reflect. Omar was frustrated by the thought that he could "make up an 'OfSTED' lesson". He outlined how he would draw on his experience to "show off" during inspection, but that trying to produce an outstanding lesson purely for the benefit for inspection was difficult if not impossible.

Inspection was present in what Omar and his colleagues did regardless of the physical presence of inspectors in the school. This was a powerful presence in a number of different ways. For example, Omar recalled an instance when in a faculty meeting he was attending the conversation turned to the possibility of implementing an online rewards system. The driver underpinning the meeting was the school's previous OfSTED inspection report. 
What I found interesting about the meeting was not that having the reward system was a good idea. It was that there wasn't any conversation about learning, or the kids. The whole driver was OfSTED want this and OfSTED want that...Don't do something just because you think the inspectors will like it. (Interview)

Omar maintained that residues of previous inspections, and preparations for the next, were ingrained in many of the discourses at the school. Omar's data revealed the omnipresence of the inspector at Long Ridge Park, and the effect of this virtual inspector upon major strategic decisions. Whilst Omar found this understandable, such drivers did not sit well with his own philosophical position as he wanted to be outstanding for himself and his students rather than fabricate this for the benefit of inspectors.

The notion of 'outstandingness' was a powerful one. The school's SLT made it clear that outstanding was the grade which was not just an aim, but the expectation, to be achieved at the next inspection.

The classrooms in Long Ridge Park had small laminated posters which outlined the requirements for bring an outstanding student and school. (Observation)

Wrapped up in being outstanding was the impact this made on the learning of Omar's students. Students' progress was fundamental to what Omar did for them, rather than for the benefit of inspectors. However, the demonstration of progress was a key ingredient of a teacher being ranked as outstanding. Omar's view was that inspection had driven so much of what the school, and teachers, did in the quest to be outstanding that it had become fundamental for both:

...of course I want to be outstanding. I want the school to be outstanding....and I think we are. The way we care for some of the kids is amazing. But being outstanding is much more than giving the inspectors what we think they want to see. We have to be outstanding for our kids first. (Interview) 
The comments about being "true" to the students, and to himself, were particular impactful. For Omar, inspection was a tool which observed what was happening in his class. It was too hard to fabricate something for the inspector. Inspection had become such a fundamental part of what the school did that it was not additional to what teachers did day-to-day, it was integral to their activities.

\section{Discussion}

The data presented here suggests that, at least in the cases in point, inspection and the perceived conditions surrounding the successful navigation of inspection has redefined Ball's notion of fabrication. For Mia and Omar, fabrication was no longer a vehicle for packaging 'versions' (Ball, 2001) of education acceptable to inspection. For these teachers, fabrications reflected exactly what was happening in their schools as they attempted to succeed at the high stake inspection process they faced. Willow Tree and Long Ridge Park were so inspection facing that there was only one acceptable version of education; the OfSTED acceptable version. As Perryman $(2009,627)$ notes, 'the whole school is built around passing inspection, with little or no space for any initiatives, schemes or plans...not directly related to the OfSTED agenda'.

The findings here suggest that accountability was the main driver for what the two schools in this study did as the pressure to be 'outstanding' increased. Willow Tree and Long Ridge Park had transformed themselves into auditable commodities to such an extent that the macro scale policy technology of performativity had infiltrated the micro scale at the school.

Mia and Omar were adamant that they did not put on a show for OfSTED. Indeed, for them this was pejorative. What inspectors saw was the best these teachers could possible do. However, the performative inspection landscape required evidence which was ingrained in the fabric of the schools in which Mia and Omar worked. 
Summative assessment, grade levels and attainment were constantly used both to assess students learning as well as an inspection metric. Mia and Omar maintained that to be able to demonstrate what they were told was what OfSTED wanted, required deep seated procedures, practices and approaches that could not simply be turned on and off.

What both teachers thought of as putting on a show was at odds with the use of the phrase pejoratively by Wilshaw. Mia and Omar's data suggest that they did want to put on a show. That is, they wanted their lessons to be outstanding; they wanted the inspectors to see them, as Mia said, "at the top of my game". This was not a case of pulling the wool over inspector's eyes. Inspection was an opportunity for these teachers to showcase the learning happening in their classrooms and with it their abilities. Mia and Omar did not produce 'OfSTED lessons' for the day the inspectors arrived. Performative conditions were omnipresent in what these teachers did as they could not afford not to be OfSTED ready every day.

The portraits presented here resonate with how performativity works as a disciplinary system and as part of the transformation of education, schools and teachers (see Ball, 1998). The paper now explores how these two specific conditions of performativity play out in the data.

\section{Performative inspection as a disciplinary system}

Inspection mediates the disciplinary mechanisms of the omnipresent watcher and 'relentless gaze' (Peryman, 2009, 616). Moreover, the relentless gaze of Panoptic performativity has resulted in schools, and teachers, 'policing themselves' (Perryman, 2009, 614). Prominent in both data sets, and resonating with Perryman's comments, was how inspection and self-policing was incumbent in the cases in point. However, for Mia and Omar inspection was not the primary tool for mediating this self policing as they had both been self policing throughout their careers. 
Mia and Omar had a deep intrinsic sense of what learning and teaching was. This intrinsic notion of quality was their driver for self policing not the demands of OfSTED. Neither teacher was naive enough to underestimate the high stakes nature of inspection. However, to the best of their abilities, they took the inspection facing systems and procedures at their school and used them to support their own approaches. For both of them, what they did day-to-day was what should be inspected, not something manufactured for the inspection visit. There were, of course, occasions where the demands of inspection readiness impinged on what Mia and Omar did in their day-to-day work. For these teachers, systems which supposedly supported successful inspection - such as "mockSTED" - were particularly hard to navigate. The constant focus upon OfSTED readiness resulted in de-motivation, annoyance and resentment.

As Wilcox and Gray $(1996,120)$ note, schools undergo 'exacting discipline which extends over a period considerably longer than that of the inspection'. The omnipotent presence of inspection had a fundamental effect upon Mia and Omar's practice. However, for both teachers, the prime driver for doing well was not in terms of external inspection. They wanted to do well for the school, for their students and for themselves. They also wanted to well during external inspection. However, the ranking of their practice during such inspection was only of any worth if it focused on what they did day in and day out. Both teachers refused to assimilate into their practice a contrived OfSTED approved checklist of what constituted an outstanding lesson. These teachers' lessons were directed, as much as possible, by their own deep seated understanding of learning and teaching.

The disconnection between what Mia and David understood to be putting on a show, that is being the best they can possibly be, and Wilshaw's pejorative use of the phrase was stark. However, Wilshaw is not alone in using metaphors such as 'playing 
the game' and 'window dressing' (DeWolf and Janssens, 2007, 382) to describe some schools' approaches toward inspection. Mia and Omar refused to approach the process of inspection in such a cynical manner. For these teachers it was just too hard to do well - both thought it should be difficult for a school to be outstanding - consequently, they were not able to manipulate the conditions of inspection success, nor did they wish to.

Concurrent with inspection being part of teachers policing themselves, was how the threat of discipline played out. For Harland $(1996,101)$, 'the exercise of continuing surveillance through the process of monitoring and evaluation means those concerned...come to discipline themselves'. Mia and Omar did not feel in danger of being disciplined, in terms of formal procedures resulting in disciplinary action, at their schools in light of inspection rankings. They were adamant that if a lesson was not successful this would not be because of negligence or being poorly prepared. This gave them the confidence that there would not be apportioning of blame.

However, this is not to say that Harland's comments did not hold in these two cases. What emerged form Mia and Omar's data was the high degree to which these teachers employed self-discipline as they were their own harshest critic. What an inspector might report would not be as critical as their own reflections. As Mia indicated, she was as likely to "beat herself up" for "not being good enough...and...failing the kids" as be overly concerned with the discipline inherent in inspection.

\section{Performative inspection as a transformationary tool}

Schools have transformed themselves to be inspection facing. This transformation resonates with Foucault's $(1963,90)$ observation that in light of inspection 'the knowing subject reorganises himself, changes himself, and begins to function in a new way'. Mia and Omar acknowledged that the pressure for them, and their schools, to transform 
themselves into OfSTED successful practitioners was considerable. In completing this transformation, the landscape became defined to an extent by what was imagined to be the requirements for a successful inspection.

This transformation took a physical, intellectual and emotional toll on both teachers (see also Jeffrey and Woods, 1998; Troman, 2000). The notion that Mia and Omar were trying to pull the wool over inspectors' eyes disregarded this toll. What was particularly telling in the data was the remorselessness with which these teachers pursued being outstanding. Crucially however, these teachers wanted to be outstanding in their terms. They had enough faith in their own abilities that these would map across to success in even the most arbitrary of inspection processes.

For these teachers, transformation was part of the process of growth in their working lives. Mia and Omar reported that the omnipresence of inspection was easily assimilated by teachers as the driver for almost every activity they completed. This was reflected in discourses around delivering the OfSTED lesson which both teachers suggested hindered creativity, risk taking and high levels of challenge necessary to be outstanding, the very qualities highlighted by OfSTED as those which inspectors wanted to see.

Mia and Omar's definition of outstanding was that it was part of their internal notion of quality, as well as being a central component of performativity and inspection. They were adamant that striving to be outstanding should not negatively impact upon their abilities to be reflective practitioners who were able to explore exciting and innovative approaches to learning and teaching. The transformation of schools and teaching by performativity imposed additional layers of surveillance which both Mia and Omar reported detracted from the inherent self inspection they employed to hone their practice. 
Ball (1998, 190) describes how teachers are inscribed in the practices of performativity as they 'attempt to fulfil competing imperatives...and inhabit irreconcilable subjectivities' (190). The competing imperatives in the cases reported here were between the systems of inspection, particularly those supposedly designed to increase the chances of success, and the personal and professional inspection inherent in Mia and Omar's teacher identities. Performativity had become so inscribed in the structures of the school that it was no longer merely a fabrication.

Ball $(2003,222)$ suggests that what inspectors might see is a 'spectacle...an "enacted fantasy" which is there to be seen and judged'. In doing so, schools can become 'an organisation for the gaze' (Ball, 1997, 332). However, the enacted fantasy, the OfSTED preferred lesson, according to Sir Michael does not exist. As a result, schools are caught in an impossible situation. Inspection success is imperative but the very core of the inspection, the lesson, is not defined in a way which makes such success achievable by clearly defined criteria. Thus, transformation occurs through a process of second guessing.

Systems and procedures designed to mediate OfSTED readiness had become the norm in both schools. Nonetheless, internal inspections using OfSTED criteria were criticised by both informants due to the time wasted in completing additional inspection facing activities. As Ball $(2001,217)$ notes, 'crucially and invariably acts of fabrication and the fabrication themselves reflect back upon the practices they stand for' with the result that fabrication becomes something to be sustained and lived up to.

\section{Conclusion}

The headline finding of this project was that both Mia and Omar wanted to be inspected, and wanted to be outstanding, but did not want to game the system to do so. They knew the inspectors would call with little notice, they knew the high-stakes which 
surrounded inspection, and they knew that to be outstanding they could not put on a fabricated show purely for the inspector's befit. For Mia and Omar, their own standards were far more exacting than those of both internal and external inspectorates.

It is important to consider the key informants' data in light of the changes to the inspection process. The 2012 amendments to the Education Act have had major implications for the efficacy of schools using fabrications to negotiate inspection. Due to the short notice inspection model, the ability of those involved in the two cases reported here to produce fabricated versions of these schools purely for the inspector was not possible. Not only was it too hard to do so, for example, post 2012 SEF data could not be fabricated for when an inspection might take place, but neither of the teachers in this study bought into fabricating events solely for the purpose of inspection even if they could do so.

This is not to say that strategies such as MockSTEAD, intervention classes for D/C GCSE borderline students, and learning walks did not take place at the two schools in question. They did. However, these strategies did not take place because OfSTED might be coming in a few years, months or even days' time as they constantly took place regardless as to whether the inspector was present or not. This OfSTED readiness impacted in deep ways upon the key informant's working lives and professional identities. Indeed performative conditions underpinned almost all of what they and their colleagues were expected to do. Both Mia and Omar positioned their practice within their own boundaries as to what an outstanding teacher and lesson was, whilst also attempting to negotiate their schools reading of what was required to attain a successful OfSTED inspection grade.

The stakes for the two schools in this study were so high in relation to inspection that they could not take chances. However, the lessons which these schools asked their 
staff to aspire to, the 'outstanding' OfSTED lesson, did not exist as a blueprint which could be replicated. Indeed, to attempt to produce a one-size-fits-all OfSTED approved lesson was just the putting on a show which so irked the Chief Inspector. The 2012 amendments ensured that the schools in question could not game the system just for the time period leading up to an inspection. These two schools, and the teachers in this study, were constantly ready for inspection with the result that fabricated conditions for inspection success became the day-to-day conditions of their working lives - what might be called conditions of post-fabrication.

Post-fabrications echo what Peryman $(2009,627)$ describes as schools running a 'completely Panoptic regime internally', No-notice inspections suggest that what inspectors see during their visit is what happens day-to-day in a school. Indeed, this is the inspection model Mia and Omar both wanted. They wanted inspection to be of what usually went on in their schools. They wanted to put on a show, but not just for the inspectors, they wanted the inspectors to see the shows they put on day-in and day-out.

However, the constant regime of inspection readiness was not one which fostered creativity and risk taking. Indeed the opposite was the case. The key informants reported that the teaching environments in their schools had become so inspection facing that identikit inspection ready lessons were promoted as the way to inspection success. In Mia and Omar's view, their schools' reliance on the OfSTED lesson had the result that inspectors could well face watching lessons which were no more than a facsimile, what Baudrillard (1994) called simulacra, of the successful OfSTED approved lesson which Wilshaw clamed did not actually exist..

For Ball, writing pre no-notice inspections, 'truthfulness is not the point' of fabrications and consequently they were 'outside the truth' (Ball, 2003, 224). Mia and Omar's lessons were not fabricated, contrived and cynical attempts to game the system 
by putting on a show fit for an inspector. Both teachers, wanted inspectors to see them teaching in the way they did for the rest of the year. Nonetheless, the teachers in this study, despite their best efforts to wrest control of the inspection process, had become 'model prisoner' (Perryman, 2009, 629) within an environment constantly prepared for the inspectors gaze. Despite the omnipresence of the inspector, these two teachers wanted to be the best they could for themselves and for their students as much as those employing panoptic surveillance of them. For Mia and Omar, their lessons were a show. Crucially however, these shows were not simulacra of OfSTED prescribed versions of teaching; they were the efforts of two people to be the best teachers they could no matter who was, or was not, watching.

\section{References}

Apple, M. (2005) Education, markets and an audit culture., Critical Quarterly, 47(12), 11-29

Ball, S. (1997) Good school/bad school: Paradox and fabrication,, British Journal of the Sociology of Education, 18(3), 317-336.

Ball, S. (1998) Performativity and fragmentation in 'postmodern schooling'. In J. Carter (Ed). Postmodernity and the fragmentation of welfare. (Florence KY, Routledge), 187-203.

Ball, S. (2001) Performativities and fabrications in the education economy: towards the performative society. In, D, Gleeson. \& C, Husbands (Eds). The performing school. Managing, teaching and learning in a performance culture (London, RoutledgeFalmer), 169-183.

Ball, S. (2003) The teacher's soul and the terrors of performativity Journal of Education Policy 18 (2), 215-228. 
Baudrillard, J. (1994) Simulacra and simulation. (S. Glaser, Trans.). (Ann Arbor: The University of Michigan Press).

British Educational Research Association (BERA). (2011) ethical guidelines for educational research. http://content.yudu.com/Library/A1t9gr/BERAEthicalGuideline/resources/index .htm?referrerUrl=http\%25253A\%25252F\%25252Fwww.yudu.com\%25252Fite m\%25252Fdetails\%25252F375952\%25252FBERA-Ethical-Guidelines-2011

Charmaz, K. (2005). Grounded Theory in the 21st Century, in: N. Denzin \& Y. Lincoln (Eds.), Handbook of Qualitative Research (3rd edn). (Thousand Oaks: Sage).

Clapham, A. (2013) Performativity, fabrication and trust: exploring computer-mediated moderation. Ethnography and Education, 8(3), 371-387

Craft, A. (2005) Creativity in schools: tensions and dilemmas (London, Routledge).

Day, C \& Gu, Q. (2010) The new lives of teachers (Abingdon. Routledge).

Delamont, S. (1976) Beyond Flanders fields: The relationship of subject matter and individuality to classroom Style, in: M. Stubbs, \& S. Delamont (Eds) Explorations in classroom observation. (London. John Wiley and Sons) 101128.

Denzin, N. (1970). The Research Act in Sociology. (Chicago: Aldine).

DeWolf. I. E. \& Janssens, F. (2007) Effects and side effects of inspection and accountability in education; an overview of empirical studies, Oxford Review of Education, 33(3), 379-396.

Fidler, B., Earley, P., Ouston, J., \& Davies, J. (1998) Teacher gratings and OfSTED inspections: Help or hindrance as a management tool? School Leadership and Management. 18(2), 257-270 
Foucault, M. (1963) The birth of the clinic: an archaeology of medical perception (London. Rutledge).

Foucault, M. (1977) Discipline and punish: the birth of the prison (London. Penguin).

Fullan, M. (2001) Leading in a culture of change (San Francisco. Jossey-Bass).

Glaser, B. \& Strauss. A (1967). The discovery of grounded theory: Strategies for qualitative research (Chicago. Aldine).

Gu, Q. \& Day, C. (2013) Challenges to teacher resilience: conditions count, British Education Research Journal. 39(1), 22-44

Hammersley, M., \& Atkinson, P. (1995). Ethnography: Principles in Practice (2nd edn.). (London: Routledge).

Harland, J. (1996) Evaluation as realpolitik, in: D. Scott \& R. Usher (Eds) Understanding educational research. (London, Routledge), 91-105.

Jeffrey, B. (2002) Performativity and primary school teacher relations. Journal of Education Policy, 17(5), 531-546

Jeffrey, B. \& Woods.P. (1998) Testing teachers. The effect of school inspectors on primary teachers (London, Falmer Press).

Jeffrey, B \& Troman, G. (2011). The Construction of Performative Identities. European Education Research Journal 10 (4): 502-515.

Jeffrey, B., \& Troman, G. 2012. Governmentality in primary schools in England. In: B Jeffrey, \& G. Troman (Eds) Performativity in UK education: Ethnographic cases of its effects, agency and reconstructions. (Stroud. E and E publishing) 87108.

Kvale, S., \& Brinkman, S. (2009). Interviews. Learning the Craft of Qualitative Research Interviewing. (London: Sage). 
Lyotard, J. (1979) The postmodern condition: A report on knowledge (G. Bennington \& B. Massumi, Trans.). (Manchester, Manchester University Press).

Morgan, M., Earley, P., Ludlow, L., Kitching, K., O’Leary, M., \& Clarke, A. (2010) What makes teachers tick? Sustaining events in new teachers' lives. British Education Research Journal. 36(2), 191-208

Nicholl, B. \& McLellan, R. (2008) 'We're all in this game whether we like it or not to get a number of As to Cs. Design technology teachers' struggles to implement creativity and performativity policies. British Educational Research Journal 34(5), 585-600

(OfSTED) Office for Standards in Education. (2011) The shape of school inspection from 2012. http://www.ofsted.gov.uk/news/shape-of-school-inspection-2012

(OfSTED) Office for Standards in Education. (2012) The framework for school inspection.https://www.education.gov.uk/publications/eOrderingDownload/0900 19.pdf

(OfSTED) Office for Standards in Education. (2014a) OfSTED to carry out no notice behaviour inspections in response to concerns of parents. http://www.ofsted.gov.uk/news/ofsted-carry-out-no-notice-behaviourinspections-response-concerns-of-parents-0. Accessed 31 Jan 2014

(OfSTED) Office for Standards in Education. (2014b) School inspection handbook. (OfSTED: Crown)

Ozga, J. (2009). Governing education through data in England: From regulation to self-evaluation. Journal of Education Policy 24, 149-162.

Policy Exchange. (2014) Watching the watchmen: The future of school inspections in England. (London: Policy Exchange) 
Priestley, M., S. Robinson \& G. Biesta. (2012). Teacher agency, performativity and curriculum change: Reinventing the teacher in the Scottish Curriculum for Excellence? In: B Jeffrey, \& G. Troman (Eds) Performativity in UK education: Ethnographic cases of its effects, agency and reconstructions. (Stroud. E and E publishing) 87-108.

Power, M. (1990) The audit society: rituals of verification. (Oxford: Oxford University Press).

Perryman, J. (2006) Panoptic performativity and school inspection regimes: disciplinary mechanisms and life under special measures, Journal of Education Policy 21(2), $147-161$.

Perryman, J. (2009) Inspection and the fabrication of professional and personal processes, Journal of Education Policy 24(5), 609-629.

Rose, N. (1999). Governing the Soul: the Shaping of the Private Self (2nd ed.). London: Free Association Books.

Scott, S. (2010). Revisiting the total institution: Performative regulation in the reinventive institution. Sociology 44 (2): 213-231.

Strauss, A., \& Corbin, J. (1998). Basics of Qualitative Research: Techniques and Procedures for Developing Grounded Theory. (Thousand Oaks: Sage).

Thomson, P., Hall, C. \& Jones. K. (2010) Maggie's day: a small-scale analysis of English education policy, Journal of Education Policy 25(5), 639-656.

Troman, G. (2000) Teacher stress in the low-trust Society, British Journal of Sociology of Education 21(3), 331-353.

Wilcox, B. \& Gray, J. (1996) Inspecting schools: Holding schools to account and helping schools to improve (Buckingham, Open University Press). 
Wilshaw, M. (2013) Key Note speech to North of England Education Conference. Sheffield, 17 January. http://www.ofsted.gov.uk/news/ofsted-chief-inspector$\underline{\text { announces-measures-tackle-local-area-under-performance-0?news }=20203}$ 